\title{
Resource Management Planning of Production Capacity
}

\author{
Dmitry Rizvanov \\ Ufa State Aviation Technical University \\ Ufa, Russian Federation \\ ridmi@mail.ru
}

\author{
Evgeniy Chernyshev \\ Ufa State Aviation Technical University \\ Ufa, Russian Federation \\ ChernyshevEvgenij@rambler.ru
}

\author{
Nafissa Yussupova \\ Ufa State Aviation Technical University \\ Ufa, Russian Federation \\ yussupova@ugatu.ac.ru
}

\begin{abstract}
Planning for the development of production facilities is necessary to ensure the effective functioning of the enterprise. To ensure the systematic development of production and the creation of new production facilities, it is proposed to use the developed software based on a multi-agent approach for information support of decision-making in the management of resources in production. A distinctive feature of the proposed software is the integration of multi-agent technologies and its own knowledge base, which allows you to take into account informal information about the subject area.
\end{abstract}

Keywords-resource management, manufacturing scheduling, multi-agent approach

\section{INTRODUCTION}

In the conditions of tough market competition, any enterprise today needs to focus on competent strategic management, innovation, production efficiency, development of high-tech products. Therefore, the main tasks of the domestic machine-building complex are: professional development of employees, investment in information technology, modernization of equipment and technologies.

However, in conditions of limited financial resources, in the modernization/organization of production to determine the required production capacity is often not enough just to directly calculate the amount of necessary equipment on the basis the technological labour input of manufacturing products. Typically, this calculation provides an ideal state of Affairs and does not take into account such important aspects of production activities as: professionalism/qualification of the employee, leave of employees, compensatory time off, sick leave, downtime of equipment related to repair, maintenance, etc., as well as other aspects related to the human factor.

For more accurate calculation of the projected/modernized production capacities it is necessary to carry out modeling of implementation of the production plan constructed taking into account various "informal" aspects of functioning of production and the saved-up knowledge bases. This approach allows to identify "bottlenecks" in the planned production. The use of multi-agent approach for solving such problems shows the high efficiency of the method. Along with the high execution speed, the calculations show the stability of the values as well as the high fault tolerance of the agents.

\section{DESCRIPTION OF THE TASK OF PLANNING THE PRODUCTION CAPACITY OF THE NEW PRODUCTION}

The situation of planning the creation of a new production for the manufacture of any products (nodes) is described.

New production is created in several main stages:

1. Determination of the composition of technological equipment;

2. Determination of the number of personnel;

3. Development of design and estimate documentation (project) for the construction (reconstruction) of the object;

4. Construction/reconstruction of the facility;

5. Technological preparation of production;

6. Equipment purchase;

7. The reception staff;

8. The exit on serial production.

Each stage of the organization has its own characteristics. The last three stages are of interest in terms of production planning.

It is planned to create a new production with a given nomenclature and a planned annual production volume of 350 sets / products per year. Reaching serial production is carried out in the following volumes:

- 1 year: 10 sets (installation batch) - the possibility of production is determined - the sufficiency of the designed equipment to carry out the entire technological chain of manufacturing the entire range of parts;

- 2 year: 50 sets;

- 3 year: 150 sets;

- 4 and subsequent years: 350 sets.

It is necessary to purchase equipment and recruit the necessary personnel for each program by the appropriate time.

III. CALCULATION OF THE NECESSARY EQUIPMENT TO PERFORM A GIVEN PROGRAM OF MANUFACTURING PARTS

Presented is the usual calculation of the necessary equipment to perform a given program of manufacture of parts (for the purpose of uniform production of DSE (parts and Assembly units), the launch party by 10 parts). Tables 1 and 2 
show the calculated data on the equipment used, as well as the laboriousness of manufacturing a given nomenclature.

For example: in order to make parts number 0487, we need three operations "CNC Turning". The first two operations, according to the technology, require a high-precision $\mathrm{CNC}$ lathe model TC600 65, and the third - a high-precision turning center machining model TC600 65 MC (Table 1). The laboriousness (table 2) of execution for operation 1.1 is as follows:

- $\quad \operatorname{Tm}=29,2 \mathrm{~min}-$ "time of work machine". Machine time takes into account only the mechanical time for processing the part - "shavings removal";

- $\mathrm{Tpf}=84 \mathrm{~min} .-$ «preliminary-final time». This time takes into account the setup of equipment for the manufacture of this detail;

- $\quad$ Tcalc $=37.6$ min. - «piece time». This time takes into account the "machine time" for each part, as well as the "pre-final time" divided by the launch batch (for example, 10 details).

A batch of identical details 0487 is made as follows: a. Equipment is being prepared: it is necessary to install and adjust the fixture, adjust the cutting and measuring tools, etc.

b. A batch of parts is made (10 pcs.). The time of processing is $-29.2 * 10=292 \mathrm{~min}$

c. Cleaning the machine and fixtures after the operation. 84 minutes are allotted for equipment preparation and cleaning.

Thus, the necessary time for the manufacture of 10 details is $84+292=376$ minutes. Consequently, the time for each detail is 37.6 minutes - «piece-calculating time». Next, we calculate the complexity of each operation for each detail for the annual project program, as well as for programs to reach the design capacity. To do this, "piecewise-calculating time" we multiply by the appropriate program; for $350: 37.60 * 350$ $=13160 \mathrm{~min}$.

The laboriousness of operations for the given programs is calculated. Table 3 is formed by combining tables 1 and 2 , grouping by equipment model and summing the laboriousness.

TABLE I. $\quad$ EQUIPMENT USED FOR THE MANUFACTURE OF THE ITEM

\begin{tabular}{|c|c|c|c|c|}
\hline \multirow{2}{*}{$\begin{array}{c}\text { № } \\
\text { Detail }\end{array}$} & № & \multirow[b]{2}{*}{ Operation name } & \multirow[b]{2}{*}{ Type of equipment } & \multirow{2}{*}{$\begin{array}{c}\text { Manufacturer, model of } \\
\text { equipment }\end{array}$} \\
\hline & № op. & & & \\
\hline 0487 & 1 & & & \\
\hline 0487 & 1.1 & Turning CNC & High precision CNC lathe & TC60065 \\
\hline 0487 & 1.2 & Turning CNC & High precision CNC lathe & TC60065 \\
\hline 0487 & 1.3 & Turning CNC & High-precision turning center & TC600 65MC \\
\hline 0114 & 2 & & & \\
\hline \multicolumn{5}{|l|}{$\ldots$} \\
\hline 9040 & 36 & & & \\
\hline 9040 & 36.1 & Turning CNC & High precision CNC lathe & TC800 110 \\
\hline 9040 & 36.2 & Drilling & Radial drilling machine & SRB 50 \\
\hline 9040 & 36.3 & Turning CNC & High precision CNC lathe & TC800 110 \\
\hline
\end{tabular}

TABLE II. THE LABORIOUSNESS OF MANUFACTURING A GIVEN NOMENCLATURES

\begin{tabular}{|c|c|c|c|c|c|c|c|c|c|}
\hline \multirow{2}{*}{$\begin{array}{c}\text { № } \\
\text { Detail }\end{array}$} & \multirow[t]{2}{*}{$\begin{array}{c}\text { № } \\
\text { № op. }\end{array}$} & \multirow[t]{2}{*}{ Operation name } & \multicolumn{3}{|c|}{$\begin{array}{c}\text { The laboriousness of the } \\
\text { operation, min }\end{array}$} & \multicolumn{4}{|c|}{$\begin{array}{c}\text { The laboriousness of the annual } \\
\text { programme, min }\end{array}$} \\
\hline & & & $\mathbf{T m}$ & Tcalc & Tpf & 10 sets & 50 sets & 150 sets & 350 sets \\
\hline 0487 & 1 & & & & & & & & \\
\hline 0487 & 1.1 & Turning CNC & 29,2 & 37,6 & 84,0 & 376,0 & 1880,0 & 5640,0 & 13160,0 \\
\hline 0487 & 1.2 & Turning CNC & 48,7 & 59,1 & 104,0 & 591,0 & 2955,0 & 8865,0 & 20685,0 \\
\hline 0487 & 1.3 & Turning CNC & 115,7 & 134,3 & 186,0 & 1343,0 & 6715,0 & 20145,0 & 47005,0 \\
\hline 0114 & 2 & & & & & & & & \\
\hline \multicolumn{10}{|l|}{$\ldots$} \\
\hline 9040 & 36 & & & & & & & & \\
\hline 9040 & 36.1 & Turning CNC & 44,5 & 55,46 & 109,6 & 554,6 & 2773,0 & 8319,0 & 19411,0 \\
\hline 9040 & 36.2 & Drilling & 14,6 & 20,07 & 54,7 & 200,7 & 1003,5 & 3010,5 & 7024,5 \\
\hline 9040 & 36.3 & Turning CNC & 104,7 & 119,22 & 145,2 & 1192,2 & 5961,0 & 17883,0 & 41727,0 \\
\hline
\end{tabular}


TABLE III. SUMMARY TABLE OF EQUIPMENT LOADING FOR THE ANNUAL PROGRAM

\begin{tabular}{|l|c|r|r|r|r|}
\hline \multirow{2}{*}{ № } & Manufacturer, model of & \multicolumn{4}{|c|}{ The laboriousness of the annual programme, min } \\
\cline { 3 - 6 } & equipment & 10 sets & \multicolumn{1}{c|}{$\mathbf{5 0}$ sets } & \multicolumn{1}{c|}{ 150 sets } & \multicolumn{1}{c|}{ 350 sets } \\
\hline 1. & C42U MT & 25964,0 & 129820,0 & 389460,0 & 908740,0 \\
\hline 2. & TC300 42 & 14403,4 & 72017,0 & 216051,0 & 504119,0 \\
\hline 3. & TC600 65 & 26463,7 & 132318,5 & 396955,5 & 926229,5 \\
\hline 4. & TC600 65 MC & 2742,0 & 13710,0 & 41130,0 & 95970,0 \\
\hline 5. & TC600 65 SMCY & 13685,0 & 68425,0 & 205275,0 & 478975,0 \\
\hline 6. & TC800 110 & 22510,2 & 112551,0 & 337653,0 & 787857,0 \\
\hline 7. & TC800 110 LMC & 600,0 & 3000,0 & 9000,0 & 21000,0 \\
\hline 8. & TC800 110MC & 9298,8 & 46494,0 & 139482,0 & 325458,0 \\
\hline 9. & TC800 77 & 15167,2 & 75836,0 & 227508,0 & 530852,0 \\
\hline 10. & SA600 & 2413,7 & 12068,5 & 36205,5 & 84479,5 \\
\hline
\end{tabular}

Different equipment of the same purpose and type has similar properties, and it is often possible to replace one with another. For this, a scheme for a possible replacement of turning equipment is formed (Fig. 1) based on their technical characteristics:

- the TC600 65 lathe can replace machine-tool CA600 (it has a CNC control system and increased accuracy), it can also replace machine-tool TC300 42 (it can manufacture larger parts. TC600 65 is more expensive than TC300 42 and much more expensive than CA600);

- the TC600 65 MC lathe can replace the TC600 65. It has the ability to install a power tool (milling cutter, drill for milling and drilling various elements in the detail);
- the TC600 65 SMCY can replace the TC600 65 $\mathrm{MC}$, it has a counter spindle and an additional $\mathrm{Y}$ axis;

- the TC800 77 can replace the TC600 65, it is larger than the TC600 65.

- the TC800 110 can replace TC800 77, it has a larger spindle diameter;

- the TC800 110MC can replace TC800 110, it has the ability to install a power tool, and differs from TC600 $65 \mathrm{MC}$ in overall dimensions and the ability to process larger details;

- the TC800 110 LMS differs from the TC800 110 in its longer length and can handle long details.

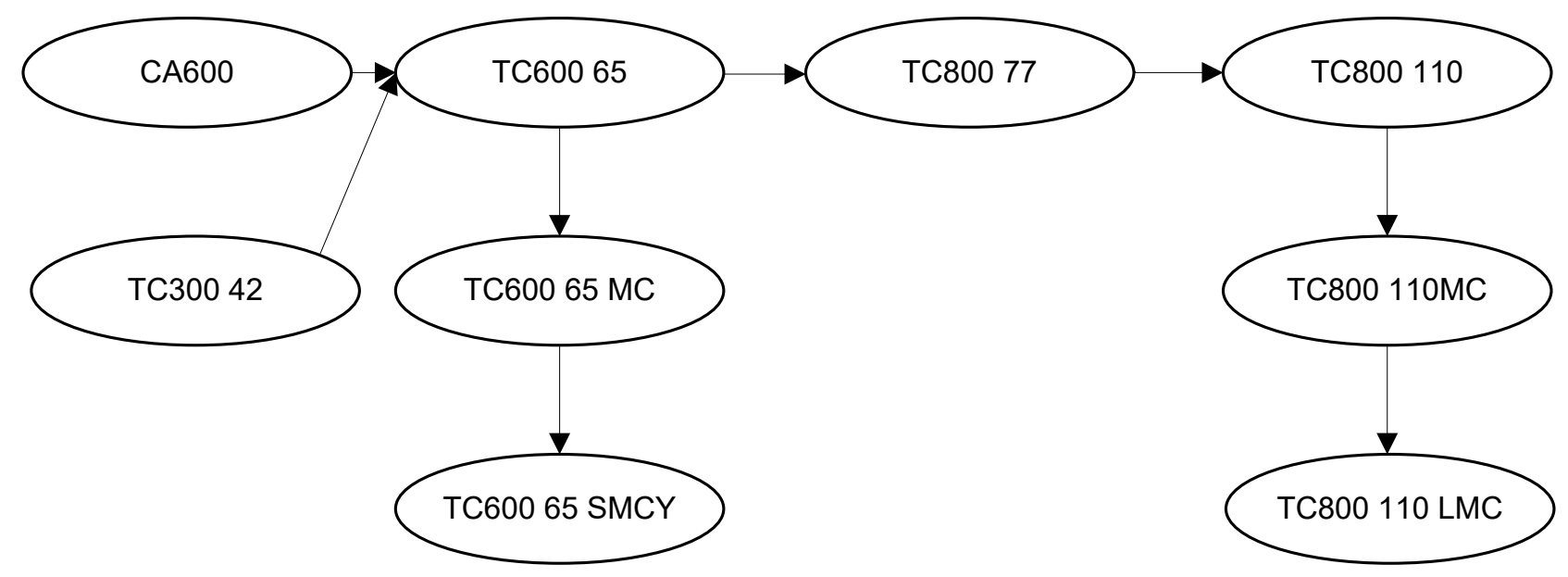

Fig. 1. Scheme of replacement of turning equipment (equipment is improved in the direction of arrows)

Next, we determine the quantity of purchased equipment based on its load.

We accept the following parameters to calculate the quantity of equipment needed:

- number of working days per year - 246;

- number of working shifts per day -2 ;
- number of hours per shift -8 ;

- maximum load ratio 0.85 .

For example, the total laboriousness for making 350 sets of production for the C42UMT milling machine was 908,740 minutes. We translate this value into hours and work shifts, which one machine should work out for the manufacture of 350 sets of DSE: 908740/60/8 = 1893.21 
work shifts. We apply the maximum load factor, we get $1893.21 * 0.85=2227.3$ work shifts. We divide the obtained value by the number of shifts per day and the number of working days per year, we get 2227.3 / 2 / $246=4.53$ machines necessary for the manufacture of 350 sets of production per year.

TABLE IV. THE RESULTS OF CALCULATING THE AMOUNT OF EQUIPMENT FOR THE ANNUAL PROGRAM 350 SETS

\begin{tabular}{|c|c|c|c|c|c|}
\hline \multirow[b]{2}{*}{ № } & \multirow{2}{*}{$\begin{array}{c}\text { Manufacturer, model of } \\
\text { equipment }\end{array}$} & \multicolumn{2}{|c|}{ Employment } & \multirow{2}{*}{$\begin{array}{c}\text { Equipment } \\
\text { quantity accepted }\end{array}$} & \multirow[b]{2}{*}{ Note } \\
\hline & & Calculated & $\begin{array}{l}\text { With the addition } \\
\text { from other equipment }\end{array}$ & & \\
\hline 1. & C42U MT & 4,53 & 4,53 & 5 & \\
\hline 2. & TC300 42 & 2,51 & 2,00 & 2 & 0,51 to item 3 \\
\hline 3. & TC60065 & 4,61 & 5,00 & 5 & 0,12 to item 5 \\
\hline 4. & TC600 65 MC & 0,48 & 0,00 & 0 & 0,48 to item 5 \\
\hline 5. & TC600 65 SMCY & 2,39 & 2,99 & 3 & \\
\hline 6. & TC800 110 & 3,92 & 3,92 & 4 & \\
\hline 7. & TC800 110 LMC & 0,10 & 0,72 & 1 & \\
\hline 8. & TC800 110MC & 1,62 & 1,00 & 1 & 0,62 to item 7 \\
\hline 9. & TC800 77 & 2,64 & 2,76 & 3 & \\
\hline 10. & SA600 & 0,42 & 0,42 & 1 & \\
\hline
\end{tabular}

Regard some positions of the Table 4:

- Pos. 2: The "own" loading of the TC300 42 is 2.51 . This means that to perform all operations where this machine is provided, the required 2.51 machines. Therefore, we increase this value to 3 machines. But you can transfer the excessive load to a better machine using Figure 1. In this case, 0.51 is transferred to the TC600 65 - pos. 3. It has an "own" load of 4.61 ( 5 machines must be bought), and the excessive load $(4.61+0.51=5.12=5+0.12) 0.12$ is transferred to the TC600 $65 \mathrm{SMCY}-$ pos. 5. The TC600 65 SMCY has its own load of 2.39 (3 machines must be bought). It is additionally "loaded" with a load of $0.48 \mathrm{~s}$ pos. 4 and $0.12 \mathrm{~s}$ pos. 3.

- Pos. 4: "own" loading of the machine TC600 65 MC was 0.48 - you need to purchase 1 machine. However, the entire load is transferred to the best machine (using Figure 1) with a low load. The "own" loading of the TC600 65 SMCY (item 5) is 2.39; therefore, the load from pos. 4 is transferred to it. There is no need to purchase a TC600 $65 \mathrm{MC}$.

- Pos. 10: The CA600 lathe has the ability to replace (according to Figure 1). CA600 is a low-cost power lathe and is designed to perform "rough" inaccurate machining of parts, so loading it cannot be transferred to the TC600 65 SMCY. But this transfer can be performed in the early stages of production development.

- The initial load calculation of 10 sets is calculated from the load for 350 sets $(\mathrm{X} / 350 * 10)$. The initial values of the column "Accepted amount of equipment" are taken equal to 0 for those rows in which, in the final calculation for 350 sets, 0 machines were taken. The calculated load is redistributed among other machines in accordance with Fig. 1.

TABLE V. THE RESUlTS OF CALCULATING THE AMOUNT OF EQUIPMENT FOR THE ANNUAL PROGRAM 10 SETS

\begin{tabular}{|l|c|c|c|c|c|}
\hline \multirow{2}{*}{ No } & \multirow{2}{*}{$\begin{array}{c}\text { Manufacturer, model of } \\
\text { equipment }\end{array}$} & \multicolumn{2}{|c|}{ Employment } & \multirow{2}{*}{$\begin{array}{c}\text { Equipment } \\
\text { quantity } \\
\text { accepted }\end{array}$} & Note \\
\cline { 3 - 5 } & Calculated & $\begin{array}{c}\text { With the addition } \\
\text { from other equipment }\end{array}$ & 1 & \\
\hline 1. & C42U MT & 0,13 & 0,13 & $0(1)^{*}$ & to item 5 \\
\hline 2. & TC300 42 & 0,07 & 0,07 & $0(1)$ & to item 5 \\
\hline 3. & TC600 65 & 0,13 & 0,13 & 0 & to item 5 \\
\hline 4. & TC600 65 MC & 0,01 & 0,01 & $0(1)$ & to item 7 \\
\hline 5. & TC600 65 SMCY & 0,07 & 0,31 & 1 & \\
\hline 6. & TC800 110 & 0,11 & 0,11 & $0(1)$ & to item 7 \\
\hline 7. & TC800 110 LMC & 0,00 & 0,24 & $0(1)$ & to item 7 \\
\hline 8. & TC800 110MC & 0,05 & 0,05 & $0(1)$ & to item 5 \\
\hline 9. & TC800 77 & 0,08 & 0,08 & & \\
\hline 10. & SA600 & 0,01 & 0,01 & & \\
\hline
\end{tabular}

*At this stage, 0 units of equipment are purchased, instead of 1 unit. 
Regard some positions of the Table 5:

- Pos. 2, 3: the load for these machines is 0.07 and 0.13, respectively, and there is a need to purchase them each for 1 machine already in the first stage. But it is more expedient to transfer their acquisition to a later date, and transfer the load to other equipment, in this case, pos. 5. The total load of the machine TC600 65 SMCY for 10 sets per year is 0.31 - you need to purchase 1 machine. Total loading of the machine TC600 65 SMCY with a load of pos. 2,3 is $0.31+0.07+0.13=0.51-$ you need to purchase 1 machine.

- Pos. 6, 8, 9 (high-precision turning lathes with $\mathrm{CNC}$ TC800 110, TC800 110MC and TC800 77): the "own" load of this equipment is $0.11,0.05$, and 0.08 are transferred to the turning center TC800 110 LMS (item 7).

- Pos. 10 (CA600 lathe): the loading of this 0.01 machine is transferred to the TC600 65 SMCY high-precision turning center (item 5).

Calculations of equipment for annual programs of 50, 150 sets are performed in a similar way.

When tables 4 and 5 are formed and the load is transferred between machines, the question always arises: "On which machine to fulfill this load?". For example, the overload of the TC300 42 can be performed on six other models of equipment: TC600 65, TC600 65 SMCY, TC800 110, TC800 110 LMS, TC800 110MC, TC80077.

\section{REVIEW OF EXISTING PLANNING SYSTEMS}

Currently, the Russian market has a number of systems scheduling workshop planning. The most famous are:

- multi-agent intra-workshop planning system "Smart Factory" (NPK "Reasonable Decisions"). The system is designed for real-time operational planning of workshop resources, including workers, machines, materials, etc. [1];

- MES-system for mechanical engineering PolyPlan (Zagidullin R.R.) - a tool for operational-calendar (workshop) planning. The system is intended for the formation of operational work schedules of equipment (schedules) both for automated production systems and for production systems with a low level of automation $[2,3]$;

- MES-system FOBOS (MSTU "Stankin", Department of "Information Technologies and Computing Systems", Doctor of Technical Sciences, Professor Frolov EB). The system solves the tasks of operational planning and supervisory control. Performs the calculation of the optimal production schedule and subsequent monitoring of its implementation. The calculation and management of the production schedule is based on a mathematical optimization apparatus that allows you to simulate 100 scenarios based on 3 selected criteria values out of 14 possible $[4,5]$;

- GOLFSTREAM automated production control system. The system generates summary analytical information for making management decisions at the strategic, tactical (shop) and operational (intra-shop) management levels [6].

These systems collect information about the implementation of the plan, equipment operation, order management, constructing a hierarchical tree of the product, setting the plan for workshops, production sites, monitoring its implementation, operational scheduling - distribution of work by performers, building diagrams of movement of details, etc. . However, these systems, both domestic and foreign, have both obvious advantages (adaptability, multicriteria scheduling, convenient input of information, output of results), and significant disadvantages, such as:

- non-availability of personnel in the subject area (production of parts is planned only for equipment);

- depersonalization of equipment - planning is carried out by work centers. A work center is a group of interchangeable machines (often the same model) with similar basic technical characteristics;

- the plan is set in the form of "how much and when to do it" without allocation of resources indicating "who will do it, on what equipment and specifically at what time" (Gulf Stream system).

The proposed approach takes into account personal characteristics of both personnel and equipment. The staff is considered separately from the equipment, and not as its integral affiliation and, therefore, it is possible to "transpose" the worker for another machine. This approach is more flexible and more adapted to real conditions and allows you to take into account the informal aspects of production.

\section{MODELING OF DEVELOPMENT OF PRODUCTION CAPACITIES OF THE ENTERPRISE}

The proposed approach allows, after calculating the amount of necessary equipment, to carry out modeling of the production plan implementation of both the maximum design and intermediate production programs. Modeling allows you to assess the adequacy of the estimated amount of equipment.

The resource distribution system created on the basis of multi-agent technologies [7,8] gives the agent "resource" [9] functions related to the calculation of production capacities, as well as some additional properties, such as cost, required estimated amount of this equipment, knowledge about the hierarchy production capabilities of equipment of this type (Fig. 1)

\section{Phases of modeling [11].}

1. Information is entered into the system on the main and intermediate annual programs for manufacturing details, about the batch of putting parts into production, the number of working days per year, the number of work shifts in days, the duration of a work shift, the maximum load factor of equipment, and other necessary information, including manufacturing technology, indicating models of the minimum necessary equipment (i.e., to perform a simple turning operation, do not lay a machine with a power tool and the function of complete milling (Y axis), but provide a simple inexpensive lathe - table 1 and 2). 
2. The system initializes the "resource" agents in the equipment calculation task mode, in an amount of 1 unit for each equipment model specified in the technologies (for this example 10 agents instances, Table 5).

3. Each agent calculates the total laboriousness input for each operation of each detail where its model of machinetool is laid down, for the implementation of the annual program and given the launch batch, they obtain summary labor costs for each equipment model for the production program for full design capacity / intermediate programs (Table 3);

4. Each agent calculates the load for the production program of full design capacity, taking into account the number of shifts, the annual fund of working time and the coefficient of maximum load (table 4, column "Estimated load");

5. Agents analyze the estimated amount of equipment by groups of equipment based on a hierarchy (starting from the expensive and functional to the simpler and cheaper):

5.1 Agent of the most expensive machine ("A1") - the last in the hierarchy for this group of machines takes the amount of equipment $=$ estimated, rounded to the nearest integer up (when loading 4.4 - 5 units are accepted).

5.2 Next, the agent "A1" calculates the "reserve" - the difference between the accepted quantity and the estimated load.

5.3 Agent "A1" passes to the next agent (with the worst model of equipment) "A2" information about the reserve on its model.

5.4 Agent "A2" subtracts "reserve" of agent "A1" from its calculated load and receives "balance".

5.5 Agent "A2" analyzes the "remainder", if it is less than or equal to zero, then for the equipment model of agent "A2" the number is 0 , and the remainder (with a positive sign) as a "reserve" goes to the next equipment model agent " A3 "(similar to step 5.3, switch-over to step 5.4, the current agent is" A3 ").

5.6 If the "remainder" is greater than zero, then the agent A2 receives the number of equipment $=$ "balance" after step 5.4 will round to the nearest whole in a big way.

5.7 Agent "A2" calculates "reserve".

5.8 All agents perform steps 5.3 through 5.7, except for the agent that simulates the latest - the worst equipment model.

6. The list of models of machine-tools is formed after step 5 with the required quantity for the production program of full design capacity (table 4, column "Accepted amount of equipment").

7. The amount of equipment needed to carry out intermediate production programs is determined by performing steps 2 - 5 for each program (Table 5). The calculation of intermediate production programs is carried out by creating in step 2 , in addition to the "resource" agent instances, an annual program of 350 sets of similar agent instances for programs 150,50 and 10 sets. The amount of equipment in the calculation of the intermediate program is limited by the maximum number of the same equipment for production programs with full design capacity and an intermediate program with a large volume of production. For example, the quantity of equipment of the "A1" resource for 350 sets be KA1 350,

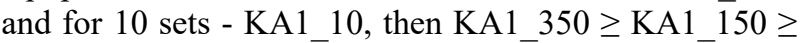
$\mathrm{KA} 1 \_50 \geq \mathrm{KA} 1 \_10$. Each resource requests information about the amount of equipment from a senior analogue according to the production program (agent A1_150 request from A1_350, and A1_10 - from A1_50, A1_150 and A1_350, etc.)

8. Data on existing / planned personnel are entered into the resource allocation system (which is created on the basis of multi-agent technologies $[7,8]$ ).

9. The implementation of the production plan is simulated (the system creates the necessary number of instances of the agents-"resource" [9] - for equipment and workers, on the basis of the given nomenclature an array of agents"detail" [9] is formed, and on the basis of manufacturing technologies - an array of agents "operation" [9]. Created agents form a schedule for manufacturing parts taking into account the task of accelerating the production of products [9], acting on the algorithms laid down in them and through negotiations [10].

10. The system generates reports in the form of a shift-daily task, schedules for loading equipment, personnel, etc.

11. The head of the production site analyzes the results, draws conclusions.

Thus, the system allows you to calculate the fulfillment of the production plan of the specified programs (for example, $10,50,150,350$ sets) for equipment and personnel that does not yet exist, determine the possibility of its implementation as a whole, view and eliminate "bottlenecks" (because one way or another they will arise in connection with the transfer of loading from one equipment to another, as well as the simultaneous start / approach of parts to processing for a particular operation). The user has the opportunity to determine a way to eliminate the "bottlenecks": by selecting more experienced personnel (that is, it is assumed that there should be a more experienced worker at the given workplace), possibly, it is only enough to organize work in overtime or purchase additional equipment and again recount the possibility of fulfilling the plan.

\section{CONCLUSION}

The problem of planning of production capacities of new production is considered. The example of calculation of production capacities for newly organized production is given. A method for solving the problem by modeling the management of production resources using a multi-agent resource allocation system is proposed.

The main difference between the proposed approach and the generally accepted ones is the use of multi-agent technologies, taking into account informal information in the calculation of production capacity, which allows to build production schedules that more accurately reflect the real production situation, improve their quality, and more accurately plan the development of production. 


\section{ACKNOWLEDGEMENT}

The research is partially supported by grants RFBR 18-0700193-a and 19-07-00895-a.

\section{REFERENCES}

[1] Rzhevskiy G. A., Skobelev P. O. How to manage complex systems? Multi-agent technology for creating of intellectual systems of management of enterprises.

[2] Zagidullin R.R. Management of machine-building production with the help of MES, APS, ERP systems: monograph / R. R. Zagidullin. Stary Oskol: TNT, 2011. - 372 p.

[3] «MES-system for mechanical engineering PolyPlan». Access mode: http://www.fobos-mes.ru/sistema-polyplan/mes-sistema-dlyamashinostroeniya-polyplan.html (accessed 05.08.2019).

[4] «MES-system «Phobos». Mode of access: http://www.fobosmes.ru/fobos-system/fobos-MES-system.html (accessed 05.08.2019).

[5] Characteristics and functions of THE MES- system Phobos. Access mode: http://www.fobos-mes.ru/fobos-system/MES-systemcharacteristic-and-functions.html (accessed 05.08.2019).

[6] Gulfstream. The focus is on production. Production planning. Access mode: http://gulfstream-mrp.ru/functions/planning/ (accessed 05.08.2019).
[7] Rizvanov D.A., Chernyshev E.S. Resource management in scheduling production processes and integration with enterprise information systems // Fundamental research. 2014. № 12 (vol. 11) pp. 2315-2319.

[8] Chernyshev E. S., Rizvanov D. A. Mathematical and information support for resource management in scheduling production processes // Modern problems of science and education. 2013. No. 6. URL: http://www.science-education.ru/113-11301 (accessed 20.09.2019).

[9] Rizvanov D. A., Chernyshev E. S. Multi-agent approach to scheduling of production processes // proceedings of the XV Baikal all-Russian with international participation conference "Information and mathematical technologies in science and management." - Irkutsk, ISEM so ran, 2010. Vol. III. - P.p. 7-14.

[10] Chernyshev E. S., Rizvanov D. A. Dataware and algorithms for scheduling of production processes // Proceedings of the XVI Baikal all-Russian conference with international participation "Information and mathematical technologies in science and management". - Irkutsk, ISEM so ran, 2011, vol. 2, Pp. 17-25.

[11] Rizvanov D. A., Chernyshev E. S. Resource management in development planning of manufacturing facilities // Proceedings of the XVI Baikal all-Russian conference with international participation "Information and mathematical technologies in science and management". - Irkutsk, ISEM SB RAS, 2016, vol. 2, Pp. 17-25. 